\title{
Erratum to: Influence of Location, Year, Potato Rotation, and Chemical Seed Treatment on Incidence and Severity of Silver Scurf on Progeny Tubers
}

\author{
Jeffrey S. Miller ${ }^{1}$ Philip B. Hamm ${ }^{2}$. \\ Jeremiah K. S. Dung ${ }^{3} \cdot$ Brad D. Geary ${ }^{4} \cdot$ Steven R. James $^{5}$. \\ Dennis A. Johnson ${ }^{6} \cdot$ Kenneth Rykbost $^{7}$
}

Published online: 20 October 2015

(C) The Potato Association of America 2015

Erratum to: Am. J. Potato Res. 92(1):62-70

DOI 10.1007/s12230-014-9412-x

In the first reference, "Bain" should be spelled "Bains". This correction should also be made where the citation appears in the text: page 63 , left-column, third paragraph and right-column, second paragraph; page 69 , right-column, first paragraph.

The online version of the original article can be found at http://dx.doi.org/ 10.1007/s12230-014-9412-x.

Jeffrey S. Miller

jeff@millerresearch.com

1 Miller Research LLC, Rupert, ID 83350, USA

2 Department. of Botany and Plant Pathology, Oregon State University, Hermiston Ag. Research \& Extension Center, Hermiston, OR 97838, USA

3 Department. of Botany and Plant Pathology, Oregon State University, Central Oregon Agricultural Research Center, Madras, OR 97741, USA

4 Brigham Young University, Provo, UT 84602, USA

5 Central Oregon Ag. Research Center, Oregon State University, Madras, OR 97741, USA

6 Washington State Univ, Pullman, WA 99164, USA

7 Formerly Oregon State University, PO Box 131, Houlton, ME 04730, USA 